\title{
A Review of Evaporative Cooling Technologies
}

\author{
O. Amer, R. Boukhanouf, and H. G. Ibrahim
}

\begin{abstract}
Air-conditioning plays an essential role in ensuring occupants thermal comfort. However, building's electricity bills have become unaffordable. Yet the commercially dominant cooling systems are intensively power-consuming ones, i.e. vapor compression systems. This paper aims to review the recent developments concerning evaporative cooling technologies that could potentially provide sufficient cooling comfort, reduce environmental impact and lower energy consumption in buildings. An extensive literature review has been conducted and mapped out the state-of-the-art evaporative cooling systems. The review covers direct evaporative cooling, indirect evaporative cooling and combined direct-indirect cooling systems. The indirect evaporative coolers include both wet-bulb temperature evaporative coolers and dew point evaporative coolers have been of particular interest because of high thermal performance. The dew point evaporative coolers have shown great potential of development and research opportunity for their improved efficiency and low energy use.
\end{abstract}

Index Terms-Evaporative cooling, effectiveness, dew point, dry bulb temperature.

\section{INTRODUCTION}

Energy demand worldwide for buildings cooling has increased sharply in the last few decades, which has raised concerns over depletion of energy resources and contributing to global warming. Current energy demand estimates stands at between 40 and $50 \%$ of total primary power consumption. In hot climate countries, the highest share of building energy use is mainly due to space air conditioning using traditional HVAC systems. For example, in the Middle East, it accounts for $70 \%$ of building energy consumption and approximately $30 \%$ of total consumption. Nowadays, buildings air conditioning has become a necessity for people life and plays a vital role in ensuring indoor comfort levels. Hence, improving the efficiency of cooling technologies are essential, particularly ones that have the potential, i.e. high performance, low power consumption [1].

Currently, mechanical vapor compression coolers (MVC) are commercially dominant despite their intensive energy use and low performance in hot climate. In contrast, evaporative cooling systems are more environmentally friendly as they consume less energy and their performance improves as air temperature increases and humidity decreases. Table I shows

Manuscript received May 4, 2014; revised June 10, 2014. This publication was made possible by NPRP grant No. 4-407-2-153 from the Qatar National Research Fund (a member of Qatar Foundation). The statements made herein are solely the responsibility of the authors.

O. Amer and R. Boukhanouf are with The University of Nottingham, Department of Built Environment, Nottingham, UK (e-mail: ezxoea@nottingham.ac.uk, rabah.boukhanouf@nottingham.ac.uk).

H. Ibrahim is with Qatar University, the Department of Architecture and Urban Planning, Doha, Qatar (e-mail: hatem_ibrahim@qu.edu.qa). a comparison of coefficient of performance (COP) values of several cooling cycles. However, the main drawback of the evaporative cooling is their high dependency on the ambient air conditions. Since the temperature difference between the dry- and wet-bulb temperatures of the ambient air is the driving force of evaporative cooling. For mild and/or humid climate this difference is small, therefore, leads to limited cooling capacity [2].

\section{EVAPORATIVE COOLING TECHNOLOGY}

Evaporative cooling is a heat and mass transfer process that uses water evaporation for air cooling, in which large amount of heat is transferred from air to water, and consequently the air temperature decreases. Evaporative coolers could be classified into: 1) Direct evaporative coolers, in which the working fluids (water and air) are in direct contact; 2) Indirect evaporative coolers, where a surface/plate separates between the working fluids; (3) Combined system of direct and indirect evaporative coolers and/or with other cooling cycles [2]. Fig. 1 illustrates a general classification of main types of evaporative cooling systems for building cooling.

TABLE I: COP VALUES OF SOME OF AIR-CONDITIONING SYSTEMS [2]

\begin{tabular}{ccccc}
\hline $\begin{array}{c}\text { System } \\
\text { type }\end{array}$ & $\begin{array}{c}\text { VMC } \\
\text { cooling }\end{array}$ & $\begin{array}{c}\text { Absorption } \\
\text { Adsorption }\end{array}$ & $\begin{array}{c}\text { Thermoelectric } \\
\text { cooling }\end{array}$ & $\begin{array}{c}\text { Evaporative } \\
\text { cooling }\end{array}$ \\
\hline COP & $2-4$ & $0.6-1.2$ & $0.2-1.2$ & $15-20$ \\
\hline \hline
\end{tabular}

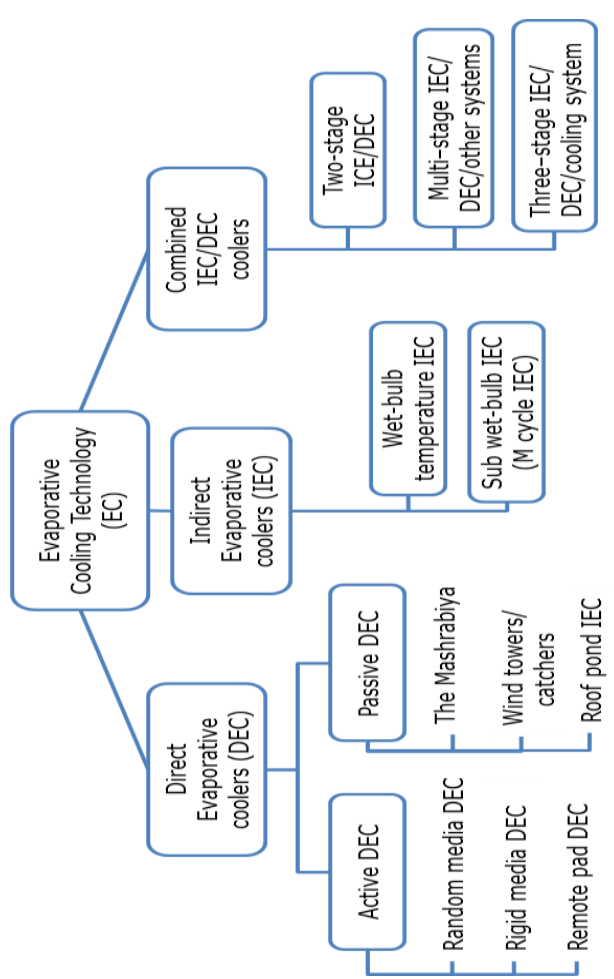

Fig. 1. A classification of evaporative cooling systems in building cooling. 


\section{Direct EVAporative CoOling (DEC)}

This system is the oldest and the simplest type of evaporative cooling in which the outdoor air is brought into direct contact with water, i.e. cooling the air by converting sensible heat to latent heat. Ingenious techniques were used thousands of years ago by ancient civilizations in variety of configurations, some of it by using earthenware jar water contained, wetted pads/canvas located in the passages of the air.

Direct evaporative coolers in buildings vary in terms of operational power consumption from zero power to high power consumption systems. DEC systems could be divided into: Active DECs which are electrically powered to operate and Passive DECs that are naturally operated systems with zero power consumption. DEC is only suitable for dry and hot climates. In moist conditions, the relative humidity can reach as high as $80 \%$, such a high humidity is not suitable for direct supply into buildings, because it may cause warping, rusting, and mildew of susceptible materials [3].

\section{A. Active DEC Systems}

The active direct evaporative coolers are electricity-driven systems, however, it use a fraction of power for air and water circulation. So, it is considered much less energy intensive than other traditional cooling technologies, with energy saving up to $90 \%$ [3]. A typical direct evaporative cooler comprises of evaporative media (wettable and porous Pads), fan blows air through the wetted medium, water tank, recirculation pump and water distribution system, as illustrated schematically in Fig. 2a. The direct evaporative cooling is an adiabatic cooling process, i.e. the total enthalpy of the air is constant throughout the process, as shown in Fig. $2 b$. The water absorbs the sensible heat from the supply air and evaporates causing the air temperature decreases and its humidity to increase [4].

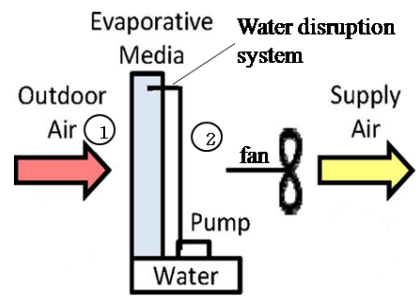

(a) Schematic structure

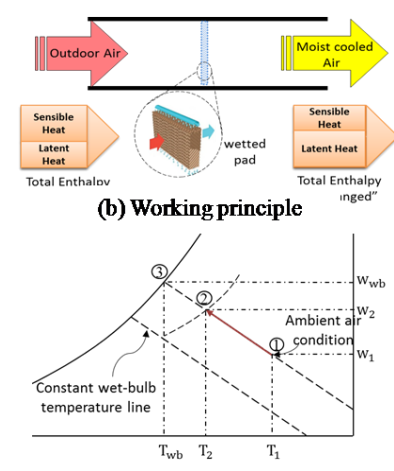

(c) Psychometric chart
Fig. 2. Structure, working principle and psychometric chart of a direct evaporative cooler [4].

Theoretically, the supply air could be cooled to $100 \%$ effectiveness, but in such process a wet-bulb effectiveness of $70 \%-80 \%$ only is achievable because of short contact time between the two fluids, insufficient wettability of the pads and due to the fact that the circulated water and the supply air will reach an equilibrium point that is equal to the wet-bulb temperature of the supply air. Eventually the system would not be able to cool down the incoming air lower than its wet-bulb temperature. The wet-bulb effectiveness could reach range between $70-95 \%$ in most current commercial
DEC coolers and mainly as a function of the type and thickness of evaporative media, working climate, and supply air flow-rate [5].

According to ASHRAE Handbook-HVAC Systems and Equipment (2008) active DEC could be divided according to types of wet media into: Random media DEC, Rigid media DEC and Remote media DEC, as shown in Fig. 3 [6]. However, active DEC coolers can be classified in terms of water distribution system type: spray (also called air washer), slinger (a rotating wheel), and drip (Misting) system [7]. Table II show the main types of active DEC systems:

\section{TABLE II: MAIN TYPES OF ACTIVE DEC SYSTEMS [6]}

\begin{tabular}{|c|c|c|c|}
\hline $\begin{array}{l}\text { System } \\
\text { type }\end{array}$ & Evaporative media & Effectiveness & Features \\
\hline $\begin{array}{l}\text { Random } \\
\text { media }\end{array}$ & $\begin{array}{l}\text { Excelsior or plastic } \\
\text { fiber/foam supported } \\
\text { by plastic frame. }\end{array}$ & $>80 \%$ & $\begin{array}{l}\text { Low } \\
\text { effectiveness } \\
\text { Short life-time. } \\
\text { Hard to clean. }\end{array}$ \\
\hline $\begin{array}{l}\text { Rigid } \\
\text { media }\end{array}$ & $\begin{array}{l}\text { Blocks of corrugated } \\
\text { materials: Cellulose, } \\
\text { plastic, fiberglass. }\end{array}$ & $75-95 \%$ & $\begin{array}{l}\text { High initial cost. } \\
\text { Longer life-time. } \\
\text { Cleaner air. }\end{array}$ \\
\hline $\begin{array}{l}\text { Remote } \\
\text { pad }\end{array}$ & $\begin{array}{l}\text { Random or rigid Pads } \\
\text { mounted on wall or } \\
\text { roof of building }\end{array}$ & $75-95 \%$ & $\begin{array}{l}\text { Higher power } \\
\text { consumption } \\
\text { Bacteria growth }\end{array}$ \\
\hline
\end{tabular}

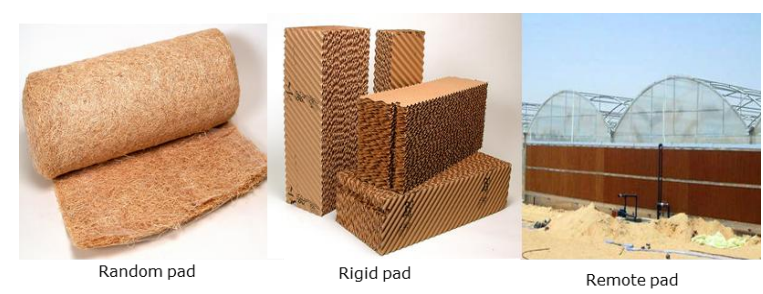

Fig. 3. Types of DEC system pads [6]

\section{B. Passive DEC Systems}

Passive cooling techniques use natural phenomena, energies, and heat sinks for cooling buildings without the use of mechanical apparatus consume electrical energy. However, small fans and pumps could be required. Passive DEC is relied on the climate which means the techniques applied for hot and humid regions are different from those for hot and arid areas. This technology is able to reduce indoor air temperature by about $9{ }^{\circ} \mathrm{C}$ [7]. The main types of passive direct evaporative cooling building integrated systems are:

\section{1) The mashrabiya}

The mashrabiya is a traditional Islamic architecture element used for natural ventilation and cooling of buildings without requiring any energy. It is wooden screens/windows provides shad, protection from the sun and allows breezes to flow through into the building for cooling purpose. Fig. 4a shows a mashrabiya system coupled with porous water-jugs to provide evaporative cooling effect for a dwelling and cooling water inside jugs for water drinking. [8].

\section{2) Wind towers}

The wind tower, also called wind catcher is a traditional passive cooling technique of buildings, existed hundreds of years ago in the Middle East and Iran, known as 'Burj al hawaa' i.e. the air tower. Basic structure of a wind tower is illustrated Fig. 4b. A capped tower with one face opening or multi-face openings at the top of tower, the tower is placed on 
the roof of a dwelling. Wind towers/catchers could be divided according airflow patterns inside the tower into: downward airflow towers and upward airflow towers.

Downward airflow wind tower, also called "Passive downdraught tower (PDEC)", is driven by pressure difference between windward side and leeward sides of the tower. The tower catches the ambient air which enters at top of the tower and flow through it to the building providing fresh air. Water could be introduced into the tower geometry by several means i.e. water pool at bottom of tower, porous jars filled with water located in the tower airstream or wetted pads hanged at the top of the tower (Fig. 4b).

Upward airflow wind tower is driven by temperature difference between building interior and the outside environment. In this system, the air is drawn upwards via wind tower. Because of positive pressure on one sides of the building the hot air could be drown down via underground channels or water fountains before entering to the building as cooled air, while the hot interior air rises upward via the openings of the wind tower [3], [8].

\section{3) Roof-pound}

Roof pond is a building-integrated evaporative cooling technique. It can contribute highly to mitigate heat by cooling the roof passively; therefore, the indoor air is cooled without increasing its moisture and reducing the energy consumption and heat gain during daytime. A typical roof pound consists of water pool in plastic or fiber-glass container stored on top of the roof of the building. The pond could be covered by a removable cover, a fixed cover or a fixed floating installation. A basic configuration of a shaded roof-pond system is shown in Fig. 4c. During summer, the ambient air flow over the pond causes the water to evaporate, thus, cools the pond and the roof structure which act as a heat sink of the building interior. During winter, the pond is emptied and the shaded openings are closed. Roof-pond cooling systems may incorporate water spraying system to enhance evaporative cooling [3].

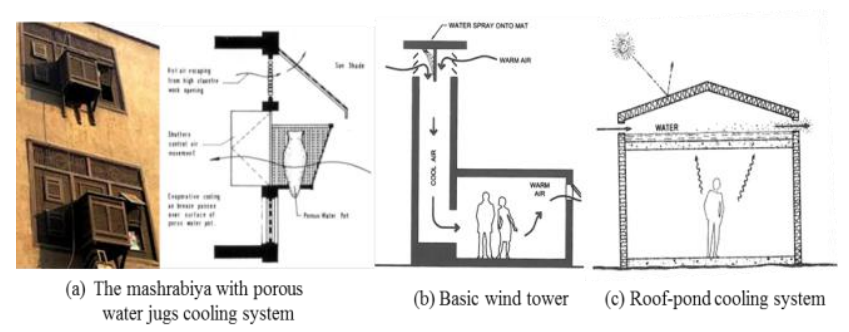

Fig. 4. Types of passive cooling systems [3].

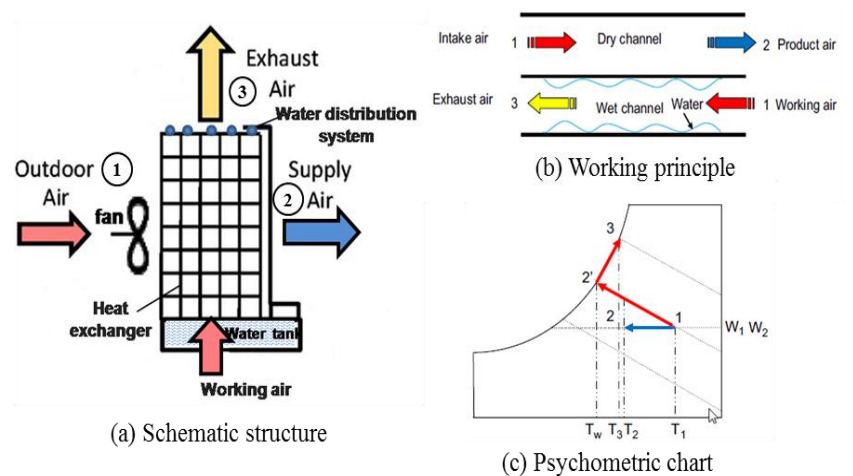

Fig. 5. IEC structure,working principle and its psychometric chart [2], [4].

\section{INDIRECT EVAPORATIVE COOLING (IEC)}

The primary idea of the indirect evaporative coolers is cooling by decreasing air sensible heat without changing its humidity, which is a distinctive advantage over DEC systems. A common IEC unit comprises of: a heat exchanger (HX), small fan, pump, water tank, and water distribution lines, as illustrated in Fig. 5a. Indirect evaporative coolers are classified into: Wet-bulb temperature IEC systems and Sub wet-bulb temperature ICE systems. [2].

\section{A. Wet-Bulb Temperature IEC System}

Wet-bulb temperature IEC system are packaged unit of flat-plate-stack, cross-flow heat exchanger, the most common configuration and flow pattern, which can lower air temperature close to, but not below, the wet-bulb temperature of the inlet air. Fig. 5b shows a schematic drawing of the working principles of a typical HX configuration of a wet-bulb temperature IEC system which comprises of several pairs of adjacent channels: wet passages of the working (secondary) air and dry passages of the supply (primary) air. Heat transfer occurs between the two working fluids through a heat conductive plate, therefore, the supply air is cooled sensibly with no additional moisture introduced into the cooled supply air stream. While, heat transfer mechanism between the working air and water in wet channels is by latent heat of water vaporization. The wet-bulb effectiveness of this system is in the range of $40-80 \%$, which is lower than that of the DEC systems [9]. Different types of IEC systems are existed which can be classified, according to the type of heat exchanger (HX), into: plate-type IEC, tubular-type IEC and heat pipe IEC as summarized below:

Plate-type HX based IEC: This type of heat exchanger is the most commonly used configuration, that is, flat-plate-stack HX with cross- or counter-flow arrangement of the primary and secondary airstreams. Fig. 6a illustrates schematically a basic plate-type IEC system. Several researches conducted evaluation of energy saving [10], [11], mathematically modeling of the heat transfer process and performance evaluation [12]-[14], studying the effects of channels dimensions, humidity ratio, primary and working air velocities, and plate wettability percentage on the efficiency of the system [15], [16]. However, the cooling effectiveness of plate type IEC system s is only in the range of $50-80 \%$.

Tubular-type HX based IEC: This configuration is usually built of circular tubes, as shown in Fig. 6b. However, other tubular shapes have been used such as elliptical and rectangular tubes [17]. A common configuration consists of a bundle of round tubes mounted in a cylindrical or rectangular shall, where the primary air flows inside the tubes and the secondary air flow across and/or along the tubes in the normal direction to the primary air, while the water is sprayed over the external surface of the tubes. So that it could offer more uniform water film over the tubes and less pressure losses comparing with plate-type IEC. Usually, the tubes are made of either polymer, metal, porous ceramic, PVC, or aluminum [5]. Another common configuration is a tube-fin HX based IEC in which round or rectangular tubes are fitted with outside fins by soldering, brazing, or welding. For example, Velasco Gomez et al. [18] introduced tube-fin HX 
based indirect evaporative cooler, that is, a bundle of porous ceramic tubes fitted with flat metallic fins. The results showed air dry-bulb temperature reduction of 9-14 ${ }^{\circ} \mathrm{C}$ was achieved. The system can be used for heat recovery in air conditioning systems [19].

Heat pipe HX based IEC: Heat pipe is a light, simple and thermally conductive device available in shapes and sizes, can be applied to transport heat from the primary to secondary air passages for cooling applications. The configuration of heat pipe can be any type from thermo-syphon, cryogenic, rotating and revolving, flat plate and capillary pumped loop heat pipe [3]. In this structure, the heat pipe based IEC, the condenser section of heat pipe is used in the secondary air (wet) channel, and the evaporator section is used in primary air (dry) channel, as shown in Fig. 7.

Limited studies [5], [20] carried out evaluating the performance of the heat pipe based IEC systems for building cooling. A finned heat pipe was used to increase convective heat transfer between the primary air and the heat pipe, with different methods of heat eliminations from the condenser sections such as water sprayer on condensation section surface, the outdoor air is precooled by air washer before passed through the condensation section, the use of porous ceramic water container fitted around condensation section to assure even distribution of water. Also, In the literature many research studies conducted on heat pipes applications in building cooling includes HVAC systems [21]-[24], and heat recovery systems [25]-[28].

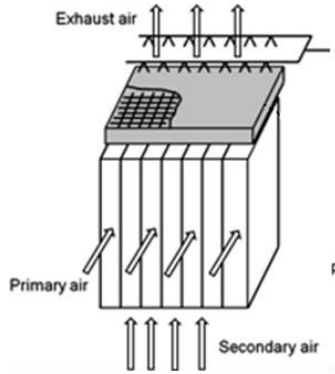

(a) Plate-type ICE

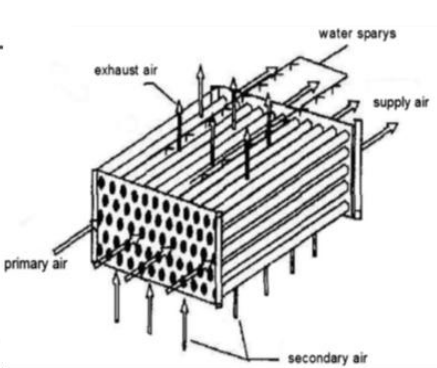

(b) Tubular-type ICE
Fig. 6. Schematics of plate-type and Tubular-type based IEC [3]

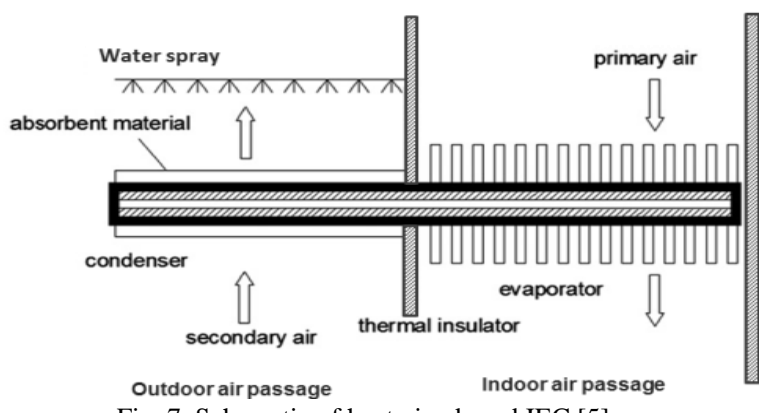

Fig. 7. Schematic of heat pipe based IEC [5]. precooled in the dry channel before it is diverted to pass through the wet channel to achieve further heat transfer with the dry channel. Thus, the primary air temperature is lower than wet-bulb temperature and approach dew-point temperature of the incoming air. So, it is called Dew point IEC. The wet-bulb effectiveness is in the range of $110 \%$ $-122 \%$ and a dew-point effectiveness of $55 \%-85 \%$. Although the M-cycle heat exchanger has 10-30\% higher effectiveness than that of the conventional heat exchangers, its operation is still facing some limitations; the secondary air is not fully cooled as high proportion of it is gradually diverted early into the wet channels, and cross-flow is unfavorable pattern for heat exchangers. An experimental tests of the M-cycle based IEC system showed that its dew-point/wet-bulb effectiveness was only around $50-60 \%$ and $80-90 \%$ respectively [30].

Several research studies conducted to develop and modify the thermal process of the M-cycle IEC to overcome the above mentioned drawbacks and to enhance the efficiency and increase the thermal performance. Zhao et al. [31] introduced a new counter-flow heat and mass exchanger based on M-cycle of a dew-point evaporative cooling system. In this structure, unlike the cross-flow Maisotsenko-cycle heat exchanger, holes are located at end of flow channels as presented in Fig. 8. The product air flows through and along the dry channels losing sensible heat to wet channels and at the end of dry channels part of cooled product air is delivered to the conditioned space and the remaining air is diverted to the adjacent wet channels as cold working air transferring heat latently with the water and sensibly with the product air in the dry channel. It was found that the wet bulb effectiveness achieve up to $130 \%$ and dew-point effectiveness of up to $90 \%$. Furthermore, a comparative study between cross-flow and counter-flow M-cycle base IEC system showed that the counter-flow arrangement achieved around $20 \%$ higher cooling capacity and 15-23\% higher dew-point and wet-bulb effectiveness respectively under the same geometrical sizes and operational conditions. Contradictory, the cross-flow exchanger has $10 \%$ higher performance which is due to an increase in power consumption of counter-flow heat exchanger [32].

Additionally, Zhao et al. [33] and [34] conducted a feasibility study in China and the UK respectively, using the proposed dew-point IEC system in [31].

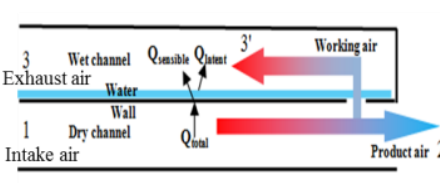

(a) Basic structure

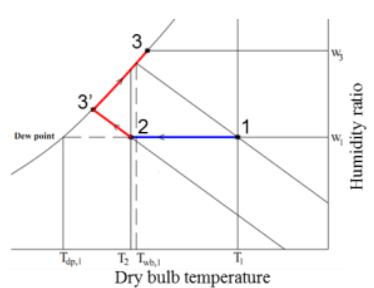

(b) Psychometric process
Fig. 8. Working principle and psychometric chart of a sub wet-bulb IEC [32]

It was found that the dew-point IEC system is applicable for most of the UK and china regions, particularly where the climate is dry. Tap water is suitable as feed water with an adequate temperature for cooling and its consumption rate ranged from 2.1 to $3 \mathrm{l} / \mathrm{kWh}$ cooling output. The system cooling output is in the range of $3.1-4.3 \mathrm{~W} / \mathrm{m}^{3} / \mathrm{h}$ air flow rate. Also, Rogdakis et al. [35] theoretically and experimentally 
evaluated the performance of an M-cycle based IEC system at Greek climate condition. It was found that the Maisotsenko cycle can be applied for most Greek cities without intensive consuming of electricity and water, the effectiveness ranged between $97 \%$ and $115 \%$, while water consumption was in the range of $2.53 .01 \mathrm{~kW} / \mathrm{h}$.

It is noteworthy that research done on the dew-point IEC systems is still at its early stage. To date, most theoretical and experimental works are based on the principles of the M-cycle. Most highly ranked papers and innovative research work of dew-point evaporative cooling systems are summarized in the following Table III.

\section{INDIRECT-DIRECT EVAPORATIVE COOLING (IDEC)}

Since DEC have higher effectiveness but humidity increases indoors while IEC have lower effectiveness and the humidity is constant, a combination of both systems or in conjunction with other cooling technologies can be a potential and achieve the best characteristics of both systems, such as cooler supply air at a lower relative humidity, higher efficiency and controlled humidity. The main components of IDEC system are heat exchanger of IEC unit, evaporative pad of DEC unit, water recirculation system, water reservoir, and blowers, as shown in Fig. 9.

TABLE III: LIST OF RECENT CONTRIBUTION AND DEVELOPMENTS OF DEW-POINT IEC SYSTEMS

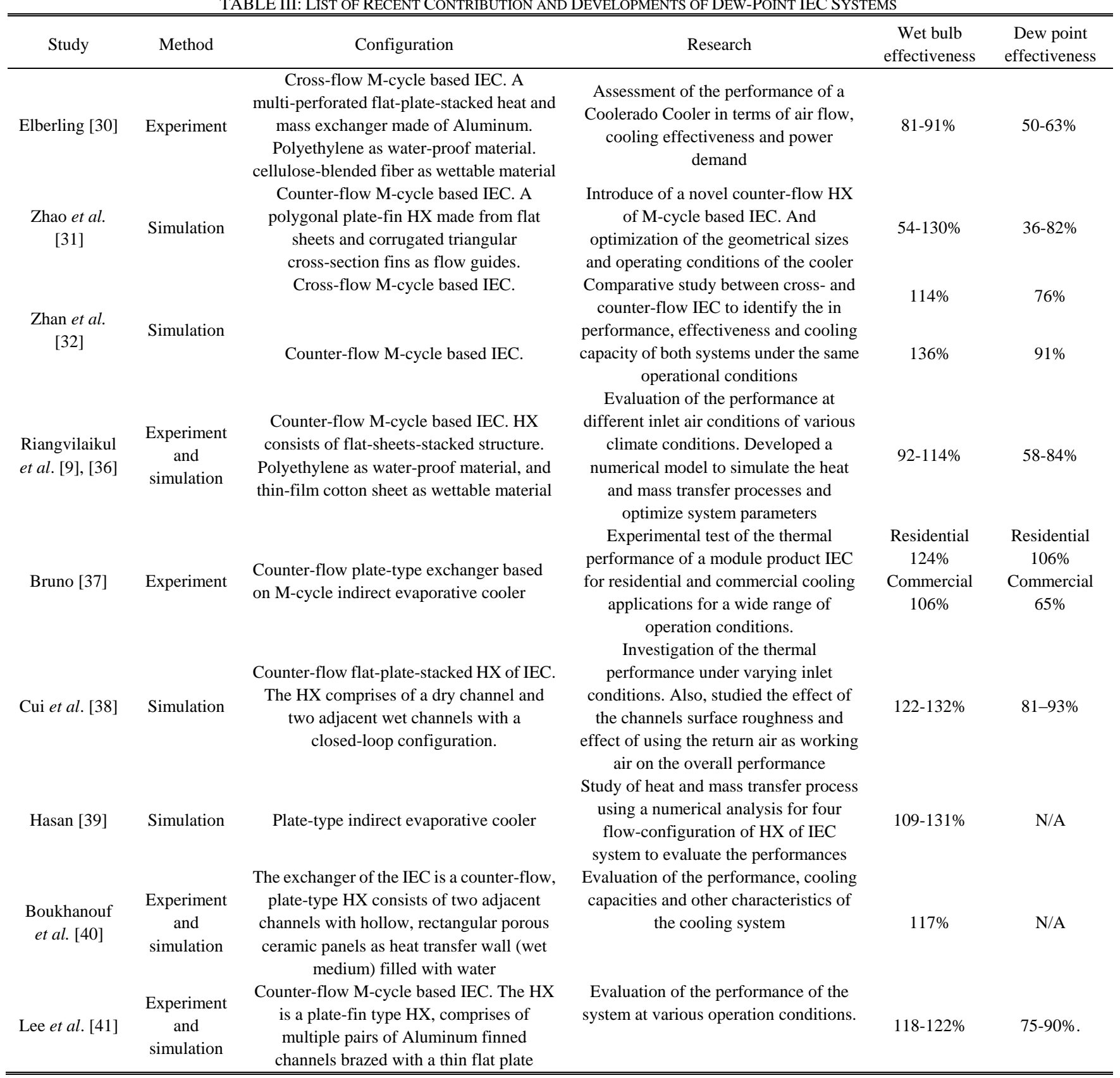

The effectiveness ranges from $90 \%$ to $115 \%$. However, the high initial cost and system complexity are the obvious drawbacks [42]. The common types of the IDEC systems are:

Two-stage IDEC: in this configuration, the IDEC comprises of IEC stage followed by a DEC stage. The first indirect stage (state 1) cools the outdoor air, which is then flows through a direct stage (state 2) for further cooling to below its wet-bulb temperature, but with additional moisture added (state 3), as illustrated on the psychometric chart Fig. $9-b$. The effectiveness is in the range of $90-120 \%$, but water consumption increases by $55 \%$ [42], [43]. Other two-stage IEC-DEC configurations reported by [44], [45] achieved 
effectiveness of 109\%-116\%.

Three-stage IDEC: this system consists of two-stage IDEC system in conjunction with a cooling cycle. For example, a solid desiccant dehumidification with an IEC and/or DEC unit [46]-[48] gives COP of around 20. Several configurations have been reported: An IEC, cooling coil and DEC stage [49], [50]. An IEC and a DEC system to provide sensible and adiabatic cooling coupled with a desiccant system for dehumidification (Fig. 10) can offer energy saving of 54\%-82\% over the conventional cooling systems [47].

Multi-stage IDEC: a hybrid system of two-stage IDEC coupled with more than one cooling cycle. For instance, combined system of two-stage DEC-IEC coupled nocturnal radiative cooling and cooling coil (Fig. 11) has higher effectiveness than two-stage evaporative cooling system, with energy saving is between $75-79 \%$ compared to MVC systems [51].

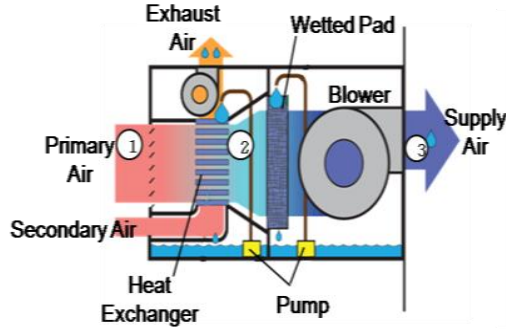

(a) Basic structure

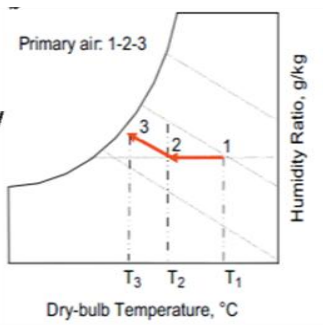

(b) Psychometric process
Fig. 9. Two-stage IDEC system [4]

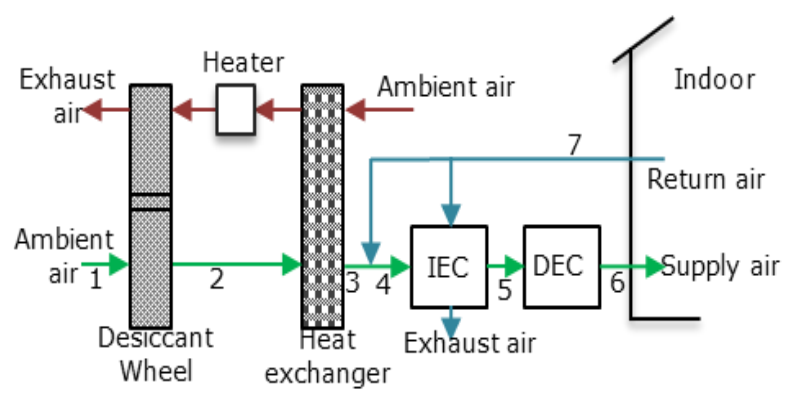

Fig. 10. Schematics of solid desiccant and evaporative cooling systems [3].

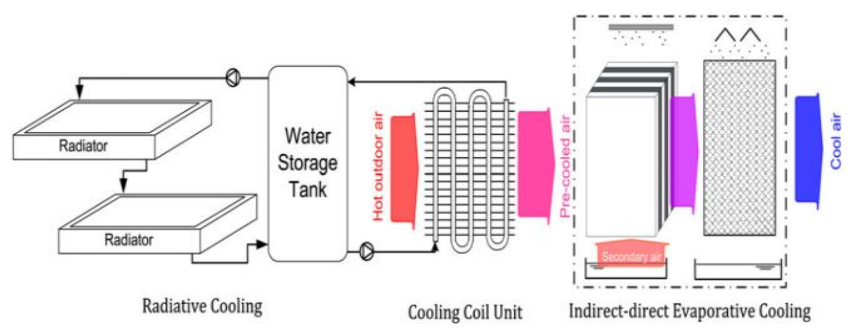

Fig. 11. Hybrid system of radiative cooling, cooling coil, and two-stage IEC-DEC system [51].

\section{CONCLUSION}

Using water for evaporation as a mean of decreasing air temperature is considerably the most environmentally friendly and effective cooling system. In this paper a review of evaporative cooling technology that could be efficiently applicable in building air-conditioning was carried out. Indirect evaporative coolers showed higher values of effectiveness and are more economical in terms of energy consumption saving, particularly the breakthrough brought about by the M-cycle based dew-point IEC system. However, combined IDEC systems have similar performance or even higher but their system's complexity and high initial cost are the major limitation. Recent works concerning indirect evaporative cooling based on Maisotsenko-cycle have shown considerable potential towards enhancing the performance and cooling capacity of IEC system for building cooling.

\section{REFERENCES}

[1] V. Vakiloroaya, B. Samali, A. Fakhar, and K. Pishghadam, "A review of different strategies for HVAC energy saving," Energy Conversion and Management, vol. 77, pp. 738-754, 2014.

[2] Z. Duan et al., "Indirect evaporative cooling: Past, present and future potentials," Renewable and Sustainable Energy Reviews, vol. 16, pp. 6823-6850, 2012.

[3] N. Lechner, Heating, Cooling, Lighting: Sustainable Design Methods for Architects, 3rd ed. New Jersey, U.S.A.: Wiley, 2009, ch. 10, pp. 276-293.

[4] T. Pistochini and M. Modera, "Water-use efficiency for alternative cooling technologies in arid climates," Energy and Buildings, vol. 43, pp. 631-638, 2011

[5] Y. M. Xuan, F. Xiao, X. F. Niu, X. Huang, and S. W. Wang, "Research and application of evaporative cooling in China: A review (I) research," Renewable and Sustainable Energy Reviews, vol. 16, pp. 3535-3546, 2012.

[6] ASHRAE Handbook HVAC Systems and Equipment (SI), $1^{\text {st }}$ ed. American Society of Heating, Refrigerating Air-Conditioning Engineers, Inc. Atlanta, GA, USA, 2008.

[7] D. Kolokotsa, M. Santamouris, A. Synnefa, and T. Karlessi, "Passive solar Architecture," Comprehensive Renewable Energy, vol. 3, pp. 637-665, 2012.

[8] F. Fardeheb, "Examination and review of passive solar cooling strategies in middle eastern and north african vernacular architecture," in Proc. ISES World Congress 2007 (Vol. I-Vol. V), Florida, 2009, pp. 2511-2515.

[9] B. Riangvilaikul and S. Kumar, "Numerical study of a novel dew point evaporative cooling system," Energy and Buildings, vol. 42, pp. 2241-2250, 2010.

[10] D. Pescod, "A heat exchanger for energy saving in an air-conditioning plant," ASHRAE Transactions, vol. 85, pp. 238-251, 1979.

[11] G. P. Maheshwari, F. Al-Ragom, and R. K. Suri, "Energy-saving potential of an indirect evaporative cooler," Applied Energy, vol. 69, pp. 69-76, 2001.

[12] I. Maclaine-Cross and P. Banks, "A general theory of wet surface heat exchangers and its application to regenerative evaporative cooling," Journal of Heat Transfer, vol. 103, pp. 579-585, 1981.

[13] J. F. J. Alonso, F. J. Martínez, E. V. Gómez, and M. A. Plasencia, "Simulation model of an indirect evaporative cooler," Energy and Buildings, vol. 29, pp. 23-27, 1998.

[14] N. J. Stoitchkov and G. I. Dimitrov, "Effectiveness of cross flow plate heat exchanger for indirect evaporative cooling," International Journal of Refrigeration, vol. 21, pp. 463-471, 1998.

[15] X. C. Guo and T. S. Zhao, "A parametric study of an indirect evaporative air cooler," International Communications in Heat and Mass Transfer, vol. 25, pp. 217-226, 1998.

[16] C. Kettleborough and C. Hsieh, "The thermal performance of the wet surface plastic plate heat exchanger used as an indirect evaporative cooler," Journal of Heat Transfer, vol. 105, pp. 366-373, 1983.

[17] D. Sekulic and R. Shah, Fundamentals of heat Exchanger Design, $1^{\text {st }}$ ed. New York, U.S.A.: Wiley, 2002, pp. 15-45.

[18] E. V. Gómez, F. J. Martínez, F.V. Diez, M. J. Leyva, and R. Martín, "Description and experimental results of a semi-indirect ceramic evaporative cooler," International Journal of Refrigeration, vol. 28. pp. 654-662, 2005 .

[19] R. H. Martín, "Numerical simulation of a semi-indirect evaporative cooler," Energy and Buildings, vol. 41, pp. 1205-1214, 2009.

[20] S. B. Riffat and J. Zhu, "Mathematical model of indirect evaporative cooler using porous ceramic and heat pipe," Applied Thermal Engineering. vol. 24, pp. 457-470, 2004.

[21] J. W. Wan, J. L. Zhang, and W. M. Zhang, "The effect of heat-pipe air-handling coil on energy consumption in central air-conditioning system," Energy and Buildings, vol. 39, pp. 1035-1040, 2007.

[22] M. A. Abd El-Baky and M. M. Mohamed, "Heat pipe heat exchanger for heat recovery in air conditioning," Applied Thermal Engineering, vol. 27 , pp. 795-801, 2007. 
[23] J. K. Calautit, H. N. Chaudhry, B. R. Hughes, and S. Abdul-Ghani, "Comparison between evaporative cooling and a heat pipe assisted thermal loop for a commercial wind tower in hot and dry climatic conditions," Applied Energy, vol. 101, pp. 740-755, 2013.

[24] J. Xu, X. Ji, W. Yang, and Z. Zhao, "Modulated porous wick evaporator for loop heat pipes: Experiment," International Journal of Heat and Mass Transfer, vol. 72, pp. 163-176, 2014.

[25] G. Mathur, "Enhancing performance of an air conditioning system with a two-phase heat recovery loop retrofit," in Proc. 31st Intersociety. Energy Conversion Engineering Conf., Washington, DC, 1996, pp. 60-67.

[26] S. H. Noie-Baghban and G. R. Majideian, "Waste heat recovery using heat pipe heat exchanger (HPHE) for surgery rooms in hospitals," Applied Thermal Engineering, vol. 20, pp. 1271-1282, 2000.

[27] R. H. Martín, F. J. Martínez, and E. V. Gómez, "Thermal comfort analysis of a low temperature waste energy recovery system: SIECHP,' Energy and Buildings, vol. 40, pp. 561-572, 2008.

[28] F. J. Martínez, M. A. Plasencia, E. V. Gómez, F. V. Díez, and R. H. Martin, "Design and experimental study of a mixed energy recovery system, heat pipes and indirect evaporative equipment for air conditioning," Energy and Buildings, vol. 35, pp. 1021-1030, 2003.

[29] V. Maisotsenko, L. E. Gillan, T. L. Heaton, and A. D. Gillan, "Method and plate apparatus for dew point evaporative cooler," U.S. Patent US6581402 B2, June 24, 2003.

[30] L. Elberling, "Laboratory Evaluation of the Coolerado cooler indirect evaporative cooling unit," Pacific Gas and Electric Company, 2006.

[31] X. Zhao, J. M. Li, and S. B. Riffat, "Numerical study of a novel counter-flow heat and mass exchanger for dew point evaporative cooling," Applied Thermal Engineering, vol. 28, pp. 1942-1951, 2008.

[32] C. Zhan et al., "Comparative study of the performance of the M-cycle counter-flow and cross-flow heat exchangers for indirect evaporative cooling - Paving the path toward sustainable cooling of buildings," Energy, vol. 36, pp. 6790-6805, 2011.

[33] X. Zhao, S. Yang, Z. Duan, and S. B. Riffat, "Feasibility study of a novel dew point air conditioning system for China building application," Building and Environment, vol. 44, pp. 1990-1999, 2009.

[34] X. Zhao, Z. Duan, C. Zhan, and S. B. Riffat, "Dynamic performance of a novel dew point air conditioning for the UK buildings," International Journal of Low-Carbon Technologies, vol. 4, pp. 27-35, 2009.

[35] E. D. Rogdakis, I. P. Koronaki, and D. N. Tertipis, "Experimental and computational evaluation of a Maisotsenko evaporative cooler at Greek climate," Energy and Buildings, vol. 70, pp. 497-506, 2014.

[36] B. Riangvilaikul, and S. Kumar, "An experimental study of a novel dew point evaporative cooling system," Energy and Buildings, vol. 42 , pp. 637-644, 2010.

[37] F. Bruno, "On-site experimental testing of a novel dew point evaporative cooler," Energy and Buildings, vol. 43, pp. 3475-3483, 2011.

[38] X. Cui et al., "Studying the performance of an improved dew-point evaporative design for cooling application," Applied Thermal Engineering, vol. 63, pp. 624-633, 2014.

[39] A. Hasan, "Indirect evaporative cooling of air to a sub-wet bulb temperature," Applied Thermal Engineering, vol. 30, pp. 2460-2468, 2010

[40] R. Boukhanouf, A. Alharbi, H. Ibrahim, and M. Kanzari, "Investigation of a sub-wet bulb temperature evaporative cooler for buildings," in Proc. 2013 Sustainable Building Conf., 2013.

[41] J. Lee and D.-Y. Lee, "Experimental study of a counter flow regenerative evaporative cooler with finned channels," International Journal of Heat and Mass Transfer, vol. 65, pp. 173-179, 2013.

[42] G. Heidarinejad, M. Bozorgmehr, S. Delfani, and J. Esmaeelian, "Experimental investigation of two-stage indirect/direct evaporative cooling system in various climatic conditions," Building and Environment, vol. 44, pp. 2073-2079, 2009.

[43] H. El-Dessouky, H. Ettouney, and A. Al-Zeefari, "Performance analysis of two-stage evaporative coolers," Chemical Engineering Journal, vol. 102, pp. 255-266, 2004.

[44] R. C. Bourne, "Development of an improved two-stage evaporative cooling system," California Energy Commission, 2004.

[45] C. Higgins et al., "Desert cool-airetm package unit technical assessment field performance of a prototype hybrid indirect evaporative air-conditioner," New Buildings Institute, 2007.

[46] M. Goldsworthy and S. White, "Optimization of a desiccant cooling system design with indirect evaporative cooler," International Journal of Refrigeration, vol. 34, pp. 148-158, 2011.

[47] G. Heidarinejad and H. Pasdarshahri, "Potential of a desiccant-evaporative cooling system performance in a multi-climate country," International Journal of Refrigeration, vol. 34, pp. 1251-1261, 2011.

[48] D. La, Y. Li, Y. J. Dai, T. S. Ge, and R. Z. Wang, "Development of a novel rotary desiccant cooling cycle with isothermal dehumidification and regenerative evaporative cooling using thermodynamic analysis method," Energy, vol. 44, pp. 778-791, 2012.

[49] M.-H Kim, J. Kim, O. Kwon, A. Choi, and J.-W. Jeong, "Energy conservation potential of an indirect and direct evaporative cooling assisted 100\% outdoor air system," Building Services Engineering Research and Technology, vol. 32, pp. 345-360, 2011.

[50] M.-H. Kim and J.-W. Jeong, "Cooling performance of a $100 \%$ outdoor air system integrated with indirect and direct evaporative coolers," Energy, vol. 52, pp. 245-257, 2013

[51] M. Farmahini-Farahani and G. Heidarinejad, "Increasing effectiveness of evaporative cooling by pre-cooling using nocturnally stored water," Applied Thermal Engineering, vol. 38, pp. 117-123, 2012.

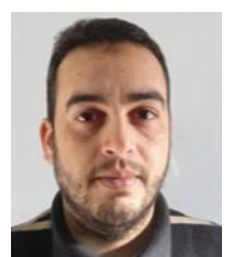

O. Amer is a $\mathrm{PhD}$ degree candidate in the Departmen of the Built Environment, University of Nottingham. His main research topic is sustainable cooling technologies. Mr. Amer has an MSc degree in new and renewable energies from University of Durham, UK 2011, BEng degree in mechanical engineering, Misurata University, Libya, 2005.

He also held a position of a lecturer in Mechanical Engineering Department, Misurata University, Libya between 2011 and 2012

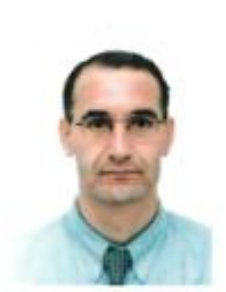

R. Boukhanouf is a lecturer in sustainable energy technologies at the Department of Built Environment, University of Nottingham. His experience in research and teaching in the area of energy efficient and low carbon technologies extends for over 15 years. $\mathrm{He}$ obtained his $\mathrm{PhD}$ degree in 1996 from the University of Manchester, UK.

Dr. Boukhanouf worked on numerous research projects funded by industry and government agencies in the area of small scale combined heat and power, active and passive heating and cooling systems for buildings, and advanced heat transfer enabling devices. He published a number of journal and conference papers and is named as the inventor in six international patents.

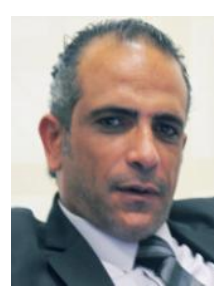

concepts.
H. G. Ibrahim is an associate professor at Qatar University. Dr. Ibrahim has a long and established research experience including managing green construction, carbon abatement in construction industry using knowledge based programming, and preservation of traditional architectural and urban heritage of Qatar. The latter being particular an ass-on advantage for reconciling the integration of new low carbon technologies with the traditional architectural 
Wastewater Treatment 
